\title{
Study on Transmission Characteristics of Vertical Rail Vibrations in Ballast Track
}

\author{
Xi Sheng, ,2 $^{\text {Caiyou Zhao, }}{ }^{1,2}$ Ping Wang, ${ }^{1,2}$ and Dongya Liu ${ }^{1,2}$ \\ ${ }^{1}$ MOE Key Laboratory of High-Speed Railway Engineering, Southwest Jiaotong University, Chengdu, China \\ ${ }^{2}$ School of Civil Engineering, Southwest Jiaotong University, Chengdu, China
}

Correspondence should be addressed to Ping Wang; wping@swjtu.edu.cn

Received 27 September 2017; Accepted 22 November 2017; Published 19 December 2017

Academic Editor: Michele Brun

Copyright (C) 2017 Xi Sheng et al. This is an open access article distributed under the Creative Commons Attribution License, which permits unrestricted use, distribution, and reproduction in any medium, provided the original work is properly cited.

A plane half-track model and a periodic track-substructure model are established. The spectral element method and spectral transfer matrix method are developed and applied to investigate the track decay rate (TDR) and transmission rate (TR) of the vertical rail vibrations, which can reflect the transmission characteristics in the longitudinal and downward directions, respectively. Furthermore, the effects of different track parameters on TDR and TR are investigated. The results show that the antiresonance frequency of the rail and the out-of-phase resonance frequency of the rail and sleeper form the boundary frequencies of the highattenuation zone for longwise vibration transmission, where the vibration absorption of the sleeper is significant. The downward transmissibility of vertical rail vibrations is greatest around the antiresonance frequency of the rail. Vertical rail vibrations are primarily transmitted in the downward direction at low frequencies, while they are mainly transmitted along the rail at high frequencies. Stiffer rail pads can make more vibrations transmitted downwards to the sleeper above the antiresonance frequency of the rail, while the changes of other track parameters have different effects on the transmission characteristics. Additionally, a field measurement is performed for verification, and the simulations are well consistent with measurements.

\section{Introduction}

The ballast track has been widely used throughout the world for years. In high-speed operation conditions, the ballast track will face many problems, such as large noises and ground-borne vibrations. They can greatly discomfort the residents. Because the energy of noises and vibrations is transmitted from the rail and vertical rail vibrations are dominant vibration sources in the straight ballast track, it is greatly significant to study the transmission characteristics of vertical rail vibrations for solving these problems.

There are two transmission directions of vertical rail vibrations: along the rail and downwards to the sleeper. TDR [1], the attenuation of vibration transmitted along the rail, reflects the transmission characteristics of rail vibrations in the longitudinal direction and controls the effective sound radiating length of the rail. TR, defined as the ratio between accelerance amplitudes of the sleeper and the on-support rail in the same section, reflects the transmission characteristics of rail vibrations in the downward direction, and it is associated with ground-borne vibrations and sleeper sound radiation. With higher TDR and TR, more rail vibrations will be transmitted downwards; with lower TDR and TR, more rail vibrations will be transmitted along the rail.

Most of the studies on the transmission of vertical rail vibrations in the ballast track only pay attention to one transmission direction. As a result, they cannot explain the interaction between vibration transmissions in different directions. Jones et al. [1] compared TDRs of different track structures according to simulations and measurements of frequency response functions. $\mathrm{Li}$ et al. [2] calculated the dispersion relation and TDRs of the ballast track with the semi-analytical finite element method, but fasteners, sleepers, and ballast were simplified as continuous supports in the model. In order to study the effects of discrete supports and section deformation on TDR, Betgen et al. [3] established a finite element model of the ballast track with the length of $34.8 \mathrm{~m}$ for the prediction. The above studies only focus on the longwise transmission characteristic of vertical rail vibrations. Knothe and $\mathrm{Wu}$ [4] investigated the receptance 
behaviors of a railway track and subgrade by a frequencydomain analysis. Zhai et al. [5] established a five-parameter model for an analysis of the ballast vibration and conducted a full-scale field experiment to measure the ballast acceleration excited by moving trains. Kaewunruen and Remennikov [6] carried out a field hammer test to analyse the experimental modals of the ballast track and evaluated the dynamic parameters of the in situ railway track components. Chebli et al. [7] built a periodic model for the soil-ballast track system and performed an in situ measurement. Vertical acceleration in several locations was obtained in the study. Esmaeili et al. [8] investigated the response of railway track to train loads while resting on an embankment. The effects of embankment parameters on dynamic responses of the rail and embankment were also studied. However, these studies mainly focus on the dynamic responses and modal characteristics of the ballast track, paying little attention to downward transmission characteristics of vertical rail vibrations.

The spectral element method (SEM) is a highly precise and efficient frequency-domain solution method where the spectral element equation is formulated in the frequencydomain and solved by using the spectral analysis method [9-11]. The procedure of the SEM is similar to that of the conventional finite element method. However, the exact dynamic stiffness matrix, known as the spectral element stiffness matrix, is formulated by using the exact wave solutions for the governing differential equations. The shape functions of SEM are frequency-dependent while those of the conventional finite element method are only determined by coordinates. In the SEM, the geometrically and materially uniform member can be replaced with only one spectral element, which reduces the total number of degrees of freedom and the calculation time [12]. The spectral transfer matrix method (STMM) is a modified transfer matrix method [13] that combines the transfer matrix method and SEM. Having the advantages of these two methods, the STMM can make a difference in studying the vibration transmission characteristics of a one-dimensional periodic structure.

In this paper, a plane half-track model and a periodic track-substructure model are established. The SEM and STMM are developed and applied to investigate the TDR and TR of the vertical rail vibrations, and the transmission characteristics are studied in the longitudinal and downward directions, simultaneously. Furthermore, the effects of different track parameters on TDR and TR are investigated. Additionally, a field measurement is performed for verification.

\section{Models and Methods}

The straight ballast track structure is used for modeling.

2.1. Plane Half-Track Model. To investigate the downward transmission characteristic of vertical rail vibrations, a plane half-track model is established to obtain the TR, as shown in Figure 1.

The model consists of a long straight rail, rail pads, sleepers (of half length), and ballast. The model length is $33 \mathrm{~m}$, and the sleeper spacing $a$ obtained from the field measurement is $55 \mathrm{~cm}$. The long rail is considered as a Timoshenko beam. To decrease the influence of wave reflections on calculation precision, nonreflecting boundary conditions are set at both ends of the rail. The fastener and ballast are both considered as a combination of a translational spring and a rotational spring: the vertical stiffness of the rail pad is $k_{\mathrm{pv}}$ and the rotational stiffness of the rail pad is $k_{\text {prot }}$; the vertical stiffness of the ballast is $k_{\mathrm{bv}}$ and the rotational stiffness of ballast is $k_{\text {brot }}$. Considering the damping of rail pads and ballast, the stiffness will be expressed in the form of complex stiffness:

$$
\begin{aligned}
& k_{\mathrm{cpv}}=k_{\mathrm{pv}}\left(1+i \eta_{\mathrm{p}}\right), \\
& k_{\mathrm{cbv}}=k_{\mathrm{bv}}\left(1+i \eta_{\mathrm{b}}\right),
\end{aligned}
$$

where $\eta_{\mathrm{p}}$ is the damping loss factor of rail pads and $\eta_{\mathrm{b}}$ is the damping loss factor of the ballast. Also, the vertical stiffness and rotational stiffness satisfy the following relation [14]:

$$
\begin{aligned}
& k_{\mathrm{cprot}}=\frac{1}{12} b_{p}^{2} k_{\mathrm{cpv}}, \\
& k_{\mathrm{cbrot}}=\frac{1}{12} b_{\mathrm{s}}^{2} k_{\mathrm{cbv}},
\end{aligned}
$$

where $b_{\mathrm{p}}$ and $b_{\mathrm{s}}$ are the lengths of the rail pad and sleeper in the longitudinal direction, respectively. The sleeper is considered as a mass block with the translational and rotational degrees of freedom. As transmission characteristics of vertical rail vibrations are inherent characteristics of the track structure, only a unit harmonic force is needed to vertically excite the rail at the middle of the model. By calculating the accelerance amplitudes of the sleeper and on-support rail in the same section, the TR can be obtained.

2.2. Spectral Element Method. The SEM is applied to solve the plane half-track model. Due to the fact that the calculation precision of SEM will not be affected by the element size, the rail between two adjacent sleepers can be modeled as only one SEM Timoshenko beam element, which will greatly reduce the calculation time. To simulate the nonreflecting boundary conditions, two Timoshenko beam throw-off elements are built at two ends of the long rail, respectively, as shown in Figure 2. The sleeper is modeled as a one-node mass element, and springs are modeled as two-node spring elements.

2.2.1. SEM Timoshenko Beam Element. The free vibration of a uniform Timoshenko beam is represented by [15]

$$
\begin{array}{r}
G A K\left(\frac{\partial^{2} v}{\partial x^{2}}-\frac{\partial \phi}{\partial x}\right)-\rho A \frac{\partial^{2} v}{\partial t^{2}}=0, \\
E I \frac{\partial^{2} \phi}{\partial x^{2}}+G A K\left(\frac{\partial v}{\partial x}-\phi\right)-\rho I \frac{\partial^{2} \phi}{\partial t^{2}}=0,
\end{array}
$$

where $G$ is the shear modulus, $A$ is the cross-sectional area, $K$ is the shear correction factor, $v$ is the transverse displacement in the $y$ direction, $\phi$ is the rotation, $\rho$ is the mass density, $E$ is Young's modulus, and $I$ is the area moment of inertia about 


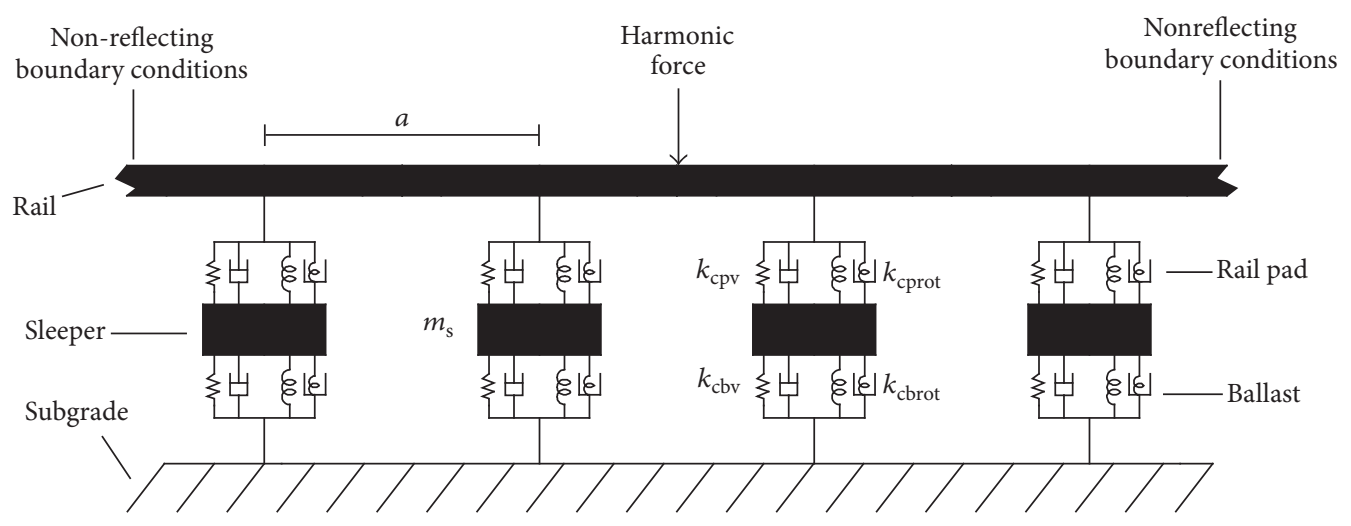

FIGURE 1: Plane half-track model.

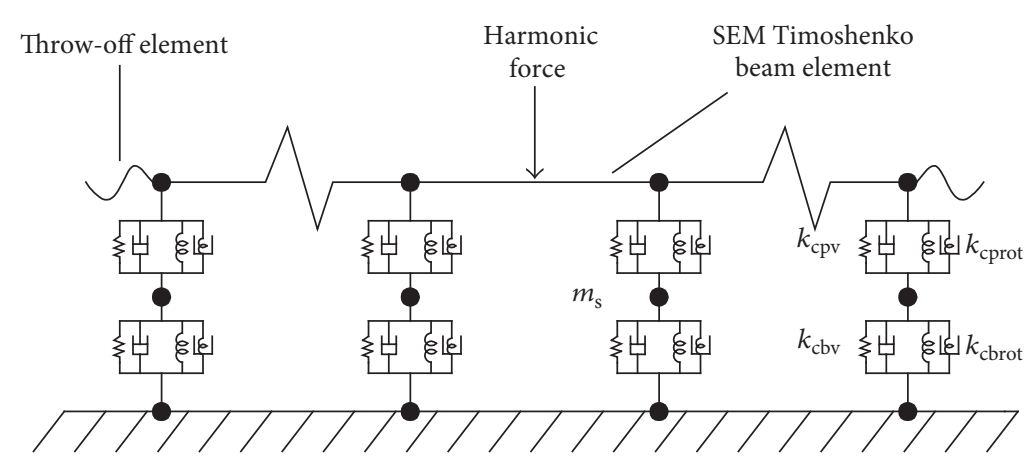

FIGURE 2: Elements of SEM.

the neutral axis. The internal bending moment and transverse shear force are given by

$$
\begin{aligned}
& V=G A K\left(\frac{\partial v}{\partial x}-\phi\right), \\
& M=E I \frac{\partial \phi}{\partial x}
\end{aligned}
$$

where $V$ is the transverse shear force and $M$ is the internal bending moment.

The solutions of (4) can be given by the spectral form:

$$
\begin{aligned}
& v(x, t)=\frac{1}{N} \sum_{n=0}^{N-1} \widehat{v}\left(x, \omega_{n}\right) e^{i \omega_{n} t} \\
& \phi(x, t)=\frac{1}{N} \sum_{n=0}^{N-1} \widehat{\phi}\left(x, \omega_{n}\right) e^{i \omega_{n} t} \\
& V(x, t)=\frac{1}{N} \sum_{n=0}^{N-1} \widehat{V}\left(x, \omega_{n}\right) e^{i \omega_{n} t} \\
& M(x, t)=\frac{1}{N} \sum_{n=0}^{N-1} \widehat{M}\left(x, \omega_{n}\right) e^{i \omega_{n} t}
\end{aligned}
$$

where $\widehat{v}, \widehat{\phi}, \widehat{V}$, and $\widehat{M}$ are the spectral displacements and forces, $N$ is the number of samples in the time domain, and $\omega_{n}$ is the angular frequency.

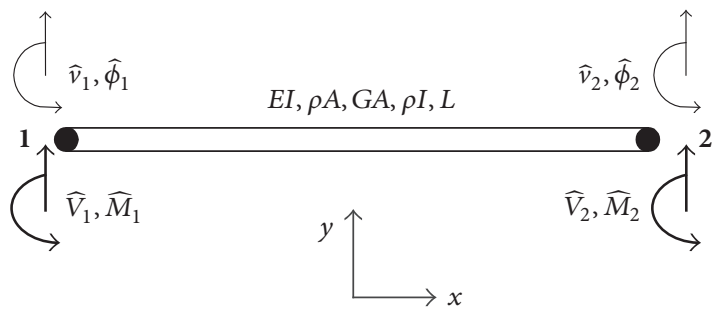

Figure 3: Spectral nodal displacements and forces of SEM Timoshenko beam element.

Spectral nodal displacements and forces of two-node SEM Timoshenko beam element are shown in Figure 3.

Substituting (5) into (3), one can obtain

$$
\begin{array}{r}
G A K\left(\frac{\partial^{2} \widehat{v}}{\partial x^{2}}-\frac{\partial \widehat{\phi}}{\partial x}\right)+\rho A \omega_{n}^{2} \widehat{v}=0, \\
E I \frac{\partial^{2} \widehat{\phi}}{\partial x^{2}}+G A K\left(\frac{\partial \widehat{v}}{\partial x}-\widehat{\phi}\right)+\rho I \omega_{n}^{2} \widehat{\phi}=0 .
\end{array}
$$

The general solutions to (6) are

$$
\begin{aligned}
& \widehat{v}\left(x, \omega_{n}\right)=v_{0} e^{-i k\left(\omega_{n}\right) x}, \\
& \widehat{\phi}\left(x, \omega_{n}\right)=\phi_{0} e^{-i k\left(\omega_{n}\right) x},
\end{aligned}
$$


where $v_{0}$ and $\phi_{0}$ are coefficients and $k\left(\omega_{n}\right)$ is the wavenumber. Substituting (7) into (6) yields an eigenvalue problem (for simplification the subscript $n$ is omitted):

$$
\left[\begin{array}{cc}
G A K k^{2}-\rho A \omega^{2} & -i G A K k \\
i G A K k & E I k^{2}+G A K-\rho I \omega^{2}
\end{array}\right]\left(\begin{array}{l}
v_{0} \\
\phi_{0}
\end{array}\right)=0 .
$$

Equation (8) gives a dispersion relation as

$$
\begin{aligned}
k^{4}-a_{1} k^{2}+a_{2} & =0, \\
a_{1} & =\frac{1}{G A K E I}\left(G A K \rho I \omega^{2}+E I \rho A \omega^{2}\right), \\
a_{2} & =\frac{\rho A \omega^{2}}{G A K E I}\left(\rho I \omega^{2}-G A K\right) .
\end{aligned}
$$

Solving (9) gives four roots as

$$
\begin{aligned}
& k_{1}=-k_{3}=\sqrt{\frac{a_{1}}{2}+\sqrt{\frac{a_{1}^{2}}{4}-a_{2}},} \\
& k_{2}=-k_{4}=\sqrt{\frac{a_{1}}{2}-\sqrt{\frac{a_{1}^{2}}{4}-a_{2}} .}
\end{aligned}
$$

From the first line of (8), one can obtain the amplitude ratio as

$$
R_{i}=\frac{v_{0}}{\phi_{0}}=\frac{i G A K k_{i}}{G A K k_{i}^{2}-\rho A \omega^{2}} \quad(i=1,2,3,4) .
$$

By combining (7), (10), and (11), the solutions of (6) can be expressed as

$$
\begin{aligned}
\widehat{v}= & R_{1} A e^{-i k_{1} x}+R_{2} B e^{-i k_{2} x}-R_{1} C e^{-i k_{1}(L-x)} \\
& -R_{2} D e^{-i k_{2}(L-x)}, \\
\widehat{\phi}= & A e^{-i k_{1} x}+B e^{-i k_{2} x}+C e^{-i k_{1}(L-x)}+D e^{-i k_{2}(L-x)},
\end{aligned}
$$

where $A, B, C$, and $D$ are coefficients determined from the boundary conditions and $L$ is the length of the beam element. The first two terms of (12) present the waves travelling to the right, and the latter two terms present the waves travelling to the left.

The boundary conditions on the element are

$$
\left(\begin{array}{l}
\widehat{v}(0, \omega) \\
\widehat{\phi}(0, \omega) \\
\widehat{v}(L, \omega) \\
\widehat{\phi}(L, \omega)
\end{array}\right)=\left(\begin{array}{c}
\widehat{v}_{1} \\
\widehat{\phi}_{1} \\
\widehat{v}_{2} \\
\widehat{\phi}_{2}
\end{array}\right)=\widehat{\mathbf{u}}_{\mathbf{t}},
$$

where $\widehat{\mathbf{u}}_{\mathbf{t}}$ is the nodal displacement vector. Substituting (12) into (13), one can obtain

$$
\begin{aligned}
& \widehat{v}(x, \omega)=\widehat{\mathbf{N}} \widehat{\mathbf{L}} \widehat{\mathbf{G}} \widehat{\mathbf{u}}_{\mathbf{t}}, \\
& \widehat{\phi}(x, \omega)=\widehat{\mathbf{N}} \widehat{\mathbf{G}} \widehat{\mathbf{u}}_{\mathbf{t}},
\end{aligned}
$$

where $\widehat{\mathbf{G}}$ is a $[4 \times 4]$ matrix:

$$
\begin{aligned}
\widehat{G}_{11} & =-\widehat{G}_{33}=\frac{\left(r_{1}+r_{2} e_{2}\right)}{\Delta}, \\
\widehat{G}_{12} & =\widehat{G}_{34}=-\frac{R_{2}\left(r_{1}-r_{2} e_{2}\right)}{\Delta}, \\
\widehat{G}_{13} & =-\widehat{G}_{31}=-\frac{\left(r_{1} e_{2}+r_{2}\right)}{\Delta}, \\
\widehat{G}_{14} & =\widehat{G}_{32}=\frac{R_{2}\left(r_{1} e_{2}-r_{2}\right)}{\Delta}, \\
\widehat{G}_{21} & =-\widehat{G}_{43}=-\frac{\left(r_{1}+r_{2} e_{1}\right)}{\Delta}, \\
\widehat{G}_{22} & =\widehat{G}_{44}=\frac{R_{1}\left(r_{1}-r_{2} e_{1}\right)}{\Delta}, \\
\widehat{G}_{23} & =-\widehat{G}_{41}=\frac{\left(r_{1} e_{1}+r_{2}\right)}{\Delta}, \\
\widehat{G}_{24} & =\widehat{G}_{42}=-\frac{R_{1}\left(r_{1} e_{1}-r_{2}\right)}{\Delta}, \\
r_{1} & =\left(R_{1}-R_{2}\right)\left(1-e_{1} e_{2}\right), \\
r_{2} & =\left(R_{1}+R_{2}\right)\left(e_{1}-e_{2}\right), \\
\Delta & =r_{1}^{2}-r_{2}^{2}, \\
e_{1} & =e^{-i k_{1} L}, \\
e_{2} & =e^{-i k_{2} L}, \\
\widehat{\mathbf{N}} & =\left(e^{-i k_{1} x} e^{-i k_{2} x} e^{-i k_{1}(L-x)} e^{-i k_{2}(L-x)}\right), \\
\widehat{\mathbf{L}} & =\operatorname{diag}\left[R_{1} \quad R_{2}-R_{1}-R_{2}\right] .
\end{aligned}
$$

From (14), we can obtain the shape functions of $\widehat{v}$ and $\widehat{\phi}$ which are $\widehat{\mathbf{N}} \widehat{\mathbf{L}} \widehat{\mathbf{G}}$ and $\widehat{\mathbf{N}} \widehat{\mathbf{G}}$, respectively. Obviously, the shape functions are frequency-dependent.

By combining (4), (5), and (14), one can obtain

$$
\begin{aligned}
& \widehat{M}(x, \omega)=E I \widehat{\mathbf{N}}^{\prime} \widehat{\mathbf{G}} \widehat{\mathbf{u}}_{\mathbf{t}}, \\
& \widehat{V}(x, \omega)=-E I \widehat{\mathbf{N}}^{\prime \prime} \widehat{\mathbf{G}}_{\mathbf{t}}-\rho I \omega^{2} \widehat{\mathbf{N}} \widehat{\mathbf{G}} \widehat{\mathbf{u}}_{\mathbf{t}} .
\end{aligned}
$$

When $x=0$ and $x=L$, the following can be obtained from (16):

$$
\left(\begin{array}{c}
-\widehat{V}(0, \omega) \\
-\widehat{M}(0, \omega) \\
\widehat{V}(L, \omega) \\
\widehat{M}(L, \omega)
\end{array}\right)=\widehat{\mathbf{H}} \widehat{\mathbf{G}}\left(\begin{array}{c}
\widehat{v}_{1} \\
\widehat{\phi}_{1} \\
\widehat{v}_{2} \\
\widehat{\phi}_{2}
\end{array}\right)=\widehat{\mathbf{f}}_{\mathbf{t}},
$$




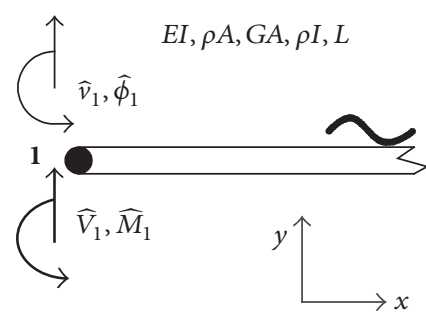

FIgURE 4: Spectral nodal displacements and forces of Timoshenko beam throw-off element.

where $\widehat{\mathbf{f}}_{\mathbf{t}}$ is the nodal displacement vector, and

$$
\widehat{\mathbf{H}}=\left(\begin{array}{c}
E I \widehat{\mathbf{N}}^{\prime \prime}(0, \omega)+\rho I \omega^{2} \widehat{\mathbf{N}}(0, \omega) \\
-E I \widehat{\mathbf{N}}^{\prime}(0, \omega) \\
-E I \widehat{\mathbf{N}}^{\prime \prime}(L, \omega)-\rho I \omega^{2} \widehat{\mathbf{N}}(L, \omega) \\
E I \widehat{\mathbf{N}}^{\prime}(L, \omega)
\end{array}\right)
$$

Since the sign convention at the left end of the Timoshenko beam element in the SEM is different from that in the strength of materials, there are minus (-) signs in front of $\widehat{V}(0, \omega)$ and $\widehat{M}(0, \omega)$ in (17). The relation between the spectral nodal forces and displacements is given by

$$
\widehat{\mathbf{f}}_{\mathbf{t}}=\mathbf{S}_{\mathbf{t}}(\omega) \widehat{\mathbf{u}}_{\mathbf{t}},
$$

where $\mathbf{S}_{\mathbf{t}}(\omega)=\widehat{\mathbf{H}} \widehat{\mathbf{G}}$ is the spectral element stiffness matrix of the Timoshenko beam. Also, $\mathbf{S}_{\mathbf{t}}(\omega)$ is frequency-dependent.

2.2.2. Timoshenko Beam Throw-Off Element. In order to reduce the impact of wave reflection on the calculation precision, throw-off elements are set at two ends of the model. In this section, we derive the spectral element stiffness matrix of Timoshenko beam throw-off element which generates no reflection waves travelling to the left. Figure 4 shows the spectral nodal displacements and forces of this one-node element.

By letting $C=D=0$ in (12), the reflection components in the solutions are removed. Therefore, the displacement solutions of the element are expressed as

$$
\begin{aligned}
& \widehat{v}=R_{1} A e^{-i k_{1} x}+R_{2} B e^{-i k_{2} x}, \\
& \widehat{\phi}=A e^{-i k_{1} x}+B e^{-i k_{2} x} .
\end{aligned}
$$

The boundary conditions $(x=0)$ on the element are

$$
\left(\begin{array}{c}
\widehat{v}(0, \omega) \\
\widehat{\phi}(0, \omega)
\end{array}\right)=\left(\begin{array}{c}
R_{1} A+R_{2} B \\
A+B
\end{array}\right)=\left(\begin{array}{c}
\widehat{v}_{1} \\
\widehat{\phi}_{1}
\end{array}\right) .
$$

From (4), (5), (20), and (21), one can obtain

$$
\left(\begin{array}{c}
-\widehat{V}(0, \omega) \\
-\widehat{M}(0, \omega)
\end{array}\right)=\mathrm{S}_{\mathbf{R}}\left(\begin{array}{l}
\widehat{v}_{1} \\
\widehat{\phi}_{1}
\end{array}\right),
$$

where

$$
\mathbf{S}_{\mathbf{R}}=\left(\begin{array}{cc}
E I \frac{k_{2}^{2}-k_{1}^{2}}{R_{1}-R_{2}} & E I \frac{R_{2} k_{1}^{2}-R_{1} k_{2}^{2}}{R_{1}-R_{2}}+\omega^{2} \rho I \\
E I \frac{i\left(k_{1}-k_{2}\right)}{R_{1}-R_{2}} & E I \frac{i\left(R_{1} k_{2}-R_{2} k_{1}\right)}{R_{1}-R_{2}}
\end{array}\right)
$$

$\mathbf{S}_{\mathbf{R}}$ is the spectral element stiffness matrix of the throw-off element.

In this paper, the derivations of the spectral element stiffness matrixes of the mass element and the spring element [16] are omitted.

2.2.3. Assembling Process. In this section, the spectral structural stiffness matrix of the whole model will be assembled. The spectral element stiffness matrix in the element coordinate can be transformed for the global coordinate using the same way as the finite element method [17]. Then, it is assembled into a spectral structural stiffness matrix, and meanwhile the constraint conditions are processed. The relation between the spectral nodal forces and displacements of the whole model can be expressed as

$$
\widehat{\mathbf{F}}=\mathbf{S}(\omega) \widehat{\mathbf{U}}
$$

where $\widehat{\mathbf{F}}$ is the spectral nodal force vector of the whole model, $\widehat{\mathbf{U}}$ is the spectral nodal displacement vector of the whole model, and $\mathbf{S}(\omega)$ is the spectral structural stiffness matrix. By solving (24), one can yield a frequency-domain analysis of the plane half-track model. The TR can be obtained through the postprocessing of the responses.

2.3. Periodic Track-Substructure Model. To investigate the transmission characteristics of vertical rail vibrations in the longitudinal direction, a periodic track-substructure model with the length of $a$ is built to obtain the TDR, as shown in Figure 5. The modeling way of track components is the same as that of the plane half-track model. Bloch's theorem [18] is used at both rail sides.

2.4. Spectral Transfer Matrix Method. The periodic tracksubstructure model is solved by using the STMM, and a fivenode calculation model is built, as shown in Figure 6 . 


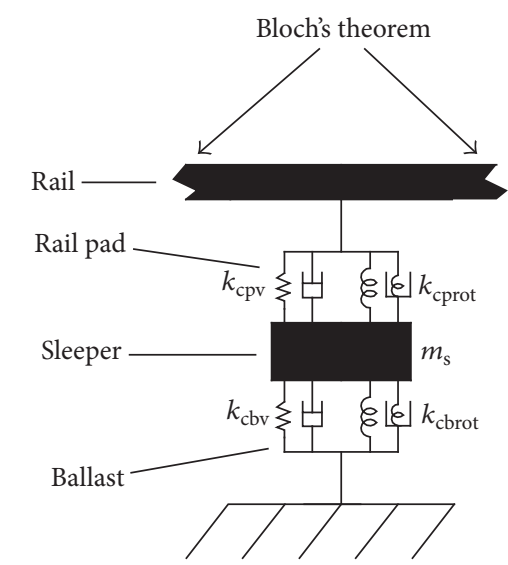

FIGURE 5: Periodic track-substructure model.

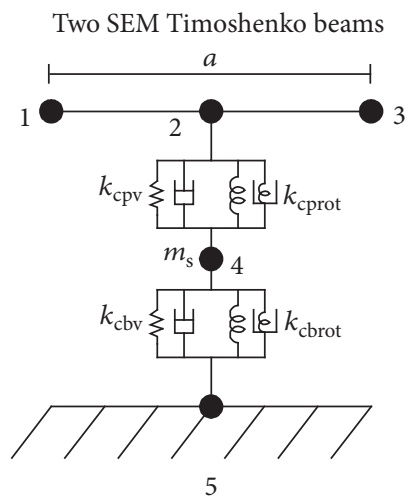

FIGURE 6: STMM elements.

The spectral structural stiffness matrix of this model is obtained by the SEM. The relation between spectral nodal forces and displacements of the whole model is shown as

$$
\left[\begin{array}{lllll}
S_{11} & S_{12} & S_{13} & S_{14} & S_{15} \\
S_{21} & S_{22} & S_{23} & S_{24} & S_{25} \\
S_{31} & S_{32} & S_{33} & S_{34} & S_{35} \\
S_{41} & S_{42} & S_{43} & S_{44} & S_{45} \\
S_{51} & S_{52} & S_{53} & S_{54} & S_{55}
\end{array}\right]\left(\begin{array}{c}
\widehat{U}_{1} \\
\widehat{U}_{2} \\
\widehat{U}_{3} \\
\widehat{U}_{4} \\
\widehat{U}_{5}
\end{array}\right)=\left(\begin{array}{c}
\widehat{F}_{1} \\
\widehat{F}_{2} \\
\widehat{F}_{3} \\
\widehat{F}_{4} \\
\widehat{F}_{5}
\end{array}\right),
$$

where $\widehat{\mathbf{U}}_{i}$ is the spectral nodal displacement vector of node $i$ and $\widehat{\mathbf{F}}_{i}$ is the spectral nodal force vector of node $i$. To build a transmission relation between the left and right nodes of the rail, the third row of the spectral structural stiffness matrix is moved to become the last row and the third column is moved to become the last column, with the corresponding modification in forces and displacements vectors. Then, the spectral structural stiffness matrix is divided to be a $3 \times 3$ matrix:

$$
\left[\begin{array}{ccc}
\mathrm{S}_{11} & \mathrm{~S}_{\mathrm{S} 12} & \mathrm{~S}_{13} \\
\mathrm{~S}_{\mathrm{S} 21} & \mathrm{~S}_{\mathrm{S} 22} & \mathrm{~S}_{\mathrm{S} 23} \\
\mathrm{~S}_{31} & \mathrm{~S}_{\mathrm{S} 32} & \mathrm{~S}_{33}
\end{array}\right]\left(\begin{array}{c}
\widehat{\mathrm{U}}_{1} \\
\widehat{\mathrm{U}}_{\mathrm{S} 2} \\
\widehat{\mathrm{U}}_{3}
\end{array}\right)=\left(\begin{array}{c}
\widehat{\mathrm{F}}_{1} \\
\widehat{\mathrm{F}}_{\mathrm{S} 2} \\
\widehat{\mathrm{F}}_{3}
\end{array}\right)
$$

where

$$
\begin{aligned}
& \mathrm{S}_{\mathrm{S} 12}=\left[\begin{array}{lll}
\mathrm{S}_{12} & \mathrm{~S}_{14} & \mathrm{~S}_{15}
\end{array}\right], \\
& \mathrm{S}_{\mathrm{S} 21}=\left[\begin{array}{lll}
\mathrm{S}_{21} & \mathrm{~S}_{41} & \mathrm{~S}_{51}
\end{array}\right]^{\mathrm{T}}, \\
& \mathrm{S}_{\mathrm{S} 22}=\left[\begin{array}{lll}
\mathrm{S}_{22} & \mathrm{~S}_{24} & \mathrm{~S}_{25} \\
\mathrm{~S}_{42} & \mathrm{~S}_{44} & \mathrm{~S}_{45} \\
\mathrm{~S}_{52} & \mathrm{~S}_{54} & \mathrm{~S}_{55}
\end{array}{ }\right. \\
& \mathrm{S}_{\mathrm{S} 23}=\left[\begin{array}{lll}
\mathrm{S}_{23} & \mathrm{~S}_{43} & \mathrm{~S}_{53}
\end{array}\right]^{\mathrm{T}}, \\
& \mathrm{S}_{\mathrm{S} 32}=\left[\begin{array}{lll}
\mathrm{S}_{32} & \mathrm{~S}_{34} & \mathrm{~S}_{35}
\end{array}\right], \\
& \widehat{\mathrm{U}}_{\mathrm{S} 2}=\left[\begin{array}{lll}
\widehat{\mathrm{U}}_{2} & \widehat{\mathrm{U}}_{4} & \widehat{\mathrm{U}}_{5}
\end{array}\right]^{\mathrm{T}}, \\
& \widehat{\mathrm{F}}_{\mathrm{S} 2}=\left[\begin{array}{lll}
\widehat{\mathrm{F}}_{2} & \widehat{\mathrm{F}}_{4} & \widehat{\mathrm{F}}_{5}
\end{array}\right]^{\mathrm{T}},
\end{aligned}
$$

Since nodes 2, 4, and 5 are free from external loads, $\widehat{\mathbf{F}}_{\mathbf{S} 2}=$ 0 . Therefore, the following can be obtained from (26):

$$
\mathrm{T}\left(\begin{array}{c}
\widehat{\mathrm{U}}_{1} \\
\widehat{\mathrm{U}}_{3}
\end{array}\right)=\left(\begin{array}{c}
-\widehat{\mathrm{F}}_{1} \\
+\widehat{\mathrm{F}}_{3}
\end{array}\right),
$$

where

$$
\begin{aligned}
T & =\left[\begin{array}{ll}
\mathrm{T}_{11} & \mathrm{~T}_{12} \\
\mathrm{~T}_{21} & \mathrm{~T}_{22}
\end{array}\right] \\
& =\left[\begin{array}{ll}
\mathrm{S}_{11}-\mathrm{S}_{\mathrm{S} 12} \mathrm{~S}_{\mathrm{S} 22}^{-1} \mathrm{~S}_{\mathrm{S} 21} & \mathrm{~S}_{13}-\mathrm{S}_{\mathrm{S} 12} \mathrm{~S}_{\mathrm{S} 22}^{-1} \mathrm{~S}_{\mathrm{S} 23} \\
\mathrm{~S}_{31}-\mathrm{S}_{\mathrm{S} 32} \mathrm{~S}_{\mathrm{S} 22}^{-1} \mathrm{~S}_{\mathrm{S} 21} & \mathrm{~S}_{33}-\mathrm{S}_{\mathrm{S} 32} \mathrm{~S}_{\mathrm{S} 22}^{-1} \mathrm{~S}_{\mathrm{S} 23}
\end{array}\right] .
\end{aligned}
$$

Let us transform (28) to

$$
\left(\begin{array}{c}
\widehat{\mathbf{U}}_{3} \\
\widehat{\mathbf{F}}_{3}
\end{array}\right)=\mathbf{t}(\omega)\left(\begin{array}{c}
\widehat{\mathbf{U}}_{1} \\
\widehat{\mathbf{F}}_{1}
\end{array}\right),
$$

where $\mathbf{t}(\omega)$ is the spectral transfer matrix:

$$
\mathbf{t}(\omega)=\left[\begin{array}{cc}
-\mathrm{T}_{12}^{-1} \mathrm{~T}_{11} & -\mathrm{T}_{12}^{-1} \\
\mathrm{~T}_{21}-\mathrm{T}_{22} \mathrm{~T}_{12}^{-1} \mathrm{~T}_{11} & -\mathrm{T}_{22} \mathrm{~T}_{12}^{-1}
\end{array}\right] .
$$

For the one-dimensional periodic track structure, Bloch's theorem [19] can be used:

$$
\left(\begin{array}{c}
\widehat{\mathbf{U}}_{3} \\
\widehat{\mathbf{F}}_{3}
\end{array}\right)=\mathrm{e}^{-i k_{x} a}\left(\begin{array}{l}
\widehat{\mathbf{U}}_{1} \\
\widehat{\mathbf{F}}_{1}
\end{array}\right),
$$

where $k_{x}$ is the one-dimensional Bloch wave vector. A standard $4 \times 4$ eigenvalue problem can be obtained from (30) and (32):

$$
\left|\mathbf{t}(\omega)-\mathrm{e}^{-i k_{x} a} \mathbf{I}\right|=0 .
$$

Thus, the dispersion relation between the wave vector $k_{x}$ and angular frequency $\omega$ can be obtained by solving the eigenvalue problem. For the bending problem of the rail, the 
TABLE 1: Model parameters.

\begin{tabular}{|c|c|c|c|}
\hline Track component & Parameter & Symbol & Value \\
\hline \multirow{6}{*}{ Rail } & Young's modulus (GPa) & $E$ & 210 \\
\hline & Shear modulus (GPa) & $G$ & 80.8 \\
\hline & Cross-sectional area $\left(\mathrm{m}^{2}\right)$ & $A$ & $7.745 \times 10^{-3}$ \\
\hline & Mass density $\left(\mathrm{kg} / \mathrm{m}^{3}\right)$ & $\rho$ & 7750 \\
\hline & Shear correction factor & K & 0.5329 \\
\hline & Area moment of inertia $\left(\mathrm{m}^{4}\right)$ & $I$ & $3.217 \times 10^{-5}$ \\
\hline \multirow{3}{*}{ Rail pad } & Vertical stiffness $(\mathrm{kN} / \mathrm{mm})$ & $k_{\mathrm{pv}}$ & 225 \\
\hline & Damping loss factor & $\eta_{\mathrm{p}}$ & 0.25 \\
\hline & Length $(\mathrm{m})$ & $b_{\mathrm{p}}$ & 0.17 \\
\hline \multirow{4}{*}{ Sleeper } & Sleeper spacing $(\mathrm{m})$ & $a$ & 0.55 \\
\hline & Mass (half sleeper) (kg) & $m_{\mathrm{s}}$ & 170 \\
\hline & Moment of inertia $\left(\mathrm{kg} \cdot \mathrm{m}^{2}\right)$ & $J$ & 1.22 \\
\hline & Length $(\mathrm{m})$ & $b_{\mathrm{s}}$ & 0.275 \\
\hline \multirow{2}{*}{ Ballast } & Vertical stiffness (per half sleeper) (kN/mm) & $k_{\mathrm{bv}}$ & 20 \\
\hline & Damping loss factor & $\eta_{\mathrm{b}}$ & 1 \\
\hline
\end{tabular}

solutions of Bloch wave vectors always appear in the form of $\pm k_{x}$ as a pair, describing the same waves travelling in opposite directions [20]. The solutions of the periodic tracksubstructure model contain two pairs of Bloch wave vectors.

Finally, the TDR can be obtained by [21]:

$$
\Delta=-8.686 \operatorname{Im}\left(k_{x}\right),
$$

where $\Delta$ stands for TDR and $\operatorname{Im}\left(k_{x}\right)$ is the imaginary part of $k_{x}$.

The same parameters are adopted in the plane half-track model and periodic track-substructure model, as shown in Table 1. The stiffness and damping loss factors of the rail pad and ballast are obtained by fitting the simulations to field hammer test measurements.

Since the cross-sectional deformation of rails occurs above $1500 \mathrm{~Hz}$ [22], the maximum simulating frequency should not be over $1500 \mathrm{~Hz}$. However, the rail is the dominant noise source at frequencies lower than $1500 \mathrm{~Hz}$, while the noise of the sleeper becomes dominant below $400 \mathrm{~Hz}[1]$. Additionally, under train load, the vertical vibration of the sleeper above $800 \mathrm{~Hz}$ is negligible [23]. Therefore, the concerned frequency range of the TDR is below $1500 \mathrm{~Hz}$ and that of the TR is below $800 \mathrm{~Hz}$ in this paper.

\section{Transmission Characteristics}

In this section, the transmission characteristics of vertical rail vibrations in ballast track are studied.

3.1. Field Measurement. A field measurement was carried out for the verification. The measurement was conducted in an existing railway line with $\mathrm{CHN} 60$ rails and concrete sleepers. The sleeper spacing is $55 \mathrm{~cm}$. In addition, the ballast tamping was just finished, and the track was in good conditions. The section selected for the measurement was far away from rail joints. The layout of the measurement is shown in Figure 7.
The sensor 1 and sensor 2 were accelerometers with the operating frequency range of $1 \sim 15000 \mathrm{~Hz}$, the nominal sensitivity of $5 \mathrm{mV} / \mathrm{g}$, and the measurement range of $1000 \mathrm{~g}$; the sensor 3 was an accelerometer with the operating frequency range of $0.2 \sim 2500 \mathrm{~Hz}$, the nominal sensitivity of $500 \mathrm{mV} / \mathrm{g}$, and the measurement range of $10 \mathrm{~g}$. The sensor 1 was placed on the mid-span railhead. The sensor 2 was placed on the onsupport railhead. And the sensor 3 was placed on the sleeper. The hammer had the measurement range of $125 \mathrm{kN}$ and the sensitivity of $0.0417 \mathrm{mV} / \mathrm{N}$. The sampling frequency of the measurement was $12800 \mathrm{~Hz}$.

By vertically exciting the middle of the mid-span railhead and acquiring the signals of the sensor 1 and hammer, the direct vertical accelerance of the mid-span rail can be obtained; by vertically exciting the middle of the on-support railhead and acquiring the signals of the sensor 2 and hammer, the direct vertical accelerance of the on-support rail can be obtained; by vertically exciting the middle of the on-support railhead and acquiring the signals of the sensor 3 and hammer, the transfer vertical accelerance of the sleeper can be obtained. Thus, the TR can be calculated from the measurements of the direct vertical accelerance of the on-support rail and the transfer vertical accelerance of the sleeper.

The TDR is measured according to the standard BS EN15461:2008+A1:2010 [24]. By vertically exciting the middle of the railheads at different distances from the sensor 1 along the rail and acquiring the signals of the sensor 1 and hammer, the direct and transfer accelerances can be obtained. Then, TDR will be calculated using these accelerance measurements. The standard gives a detailed description of the measurement procedure, exciting points, and calculation formula.

Five effective impacts are made at each exciting point, and the averages are taken for the results of each accelerance. The lower limit of the effective frequency range of the measurement depends on the coherent coefficient of the 


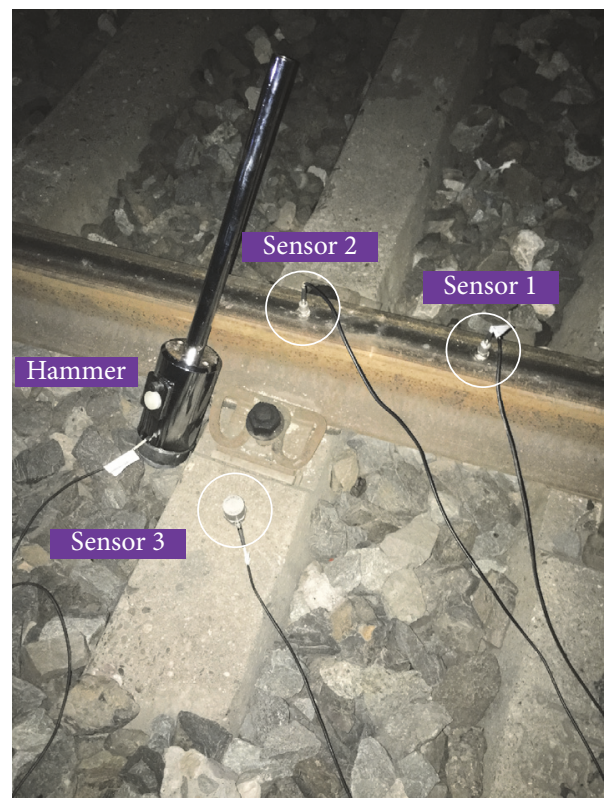

FIGURE 7: Layout of measurement sensors.
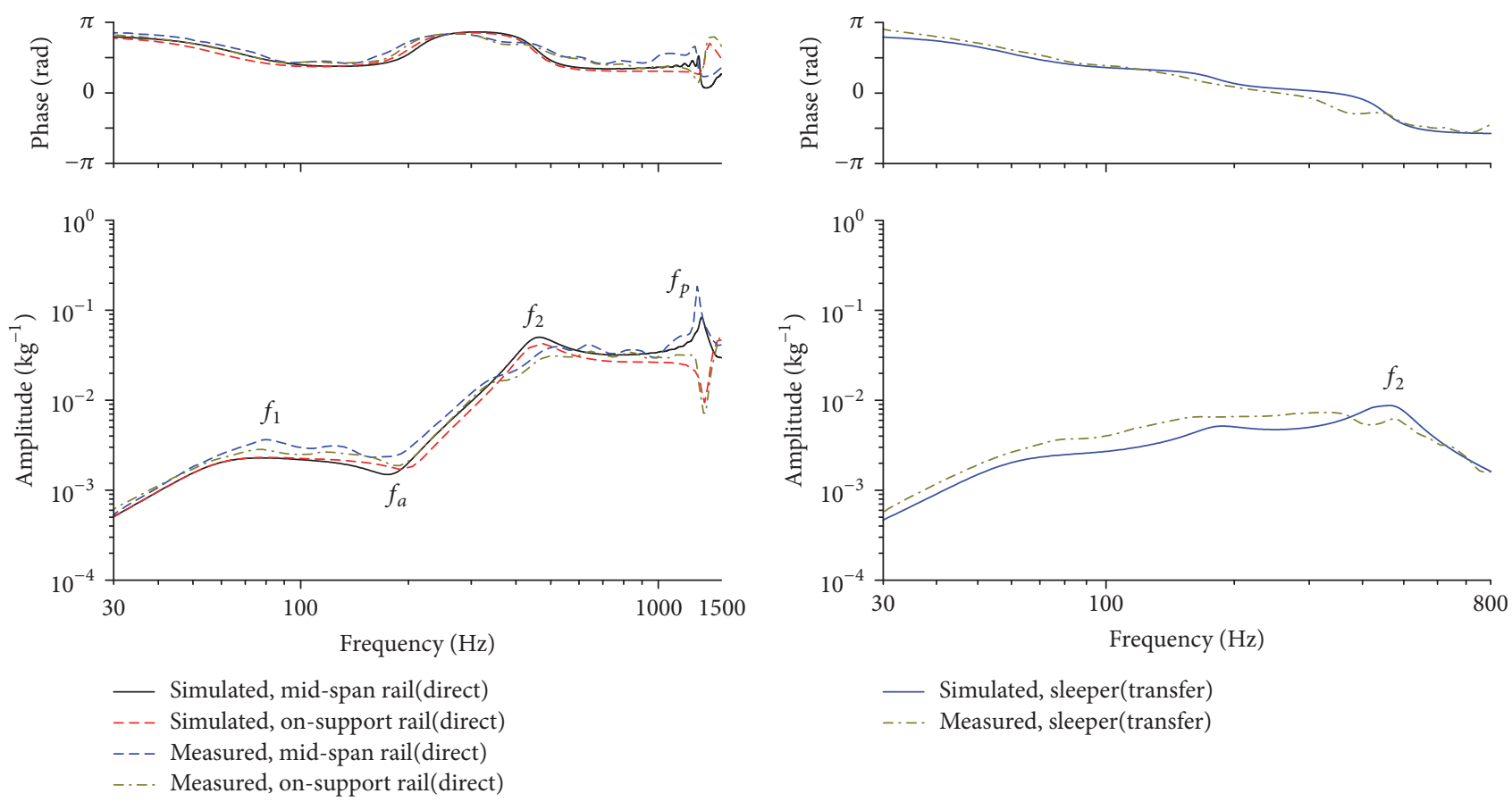

(a)

(b)

FIGURE 8: Vertical accelerances of (a) rail and (b) sleeper.

accelerance, and the coherent coefficient is required to be over 0.8 [25]; the upper limit of the effective frequency range should meet the requirement that the decrease in the autospectrum function of the force is less than $10 \mathrm{~dB}$ at this frequency [14]. Based on these rules, the effective frequency range of the field measurement is $20 \sim 2000 \mathrm{~Hz}$.
3.2. Accelerance Behavior. The accelerance behaviors are of great use to explain the trends of TDR and TR curves. The accelerances of the rail and sleeper are shown in Figure 8.

Figure 8 shows that the simulations of the vertical accelerances match measurements. The rail and sleeper have the same accelerance in the low frequency range and they 


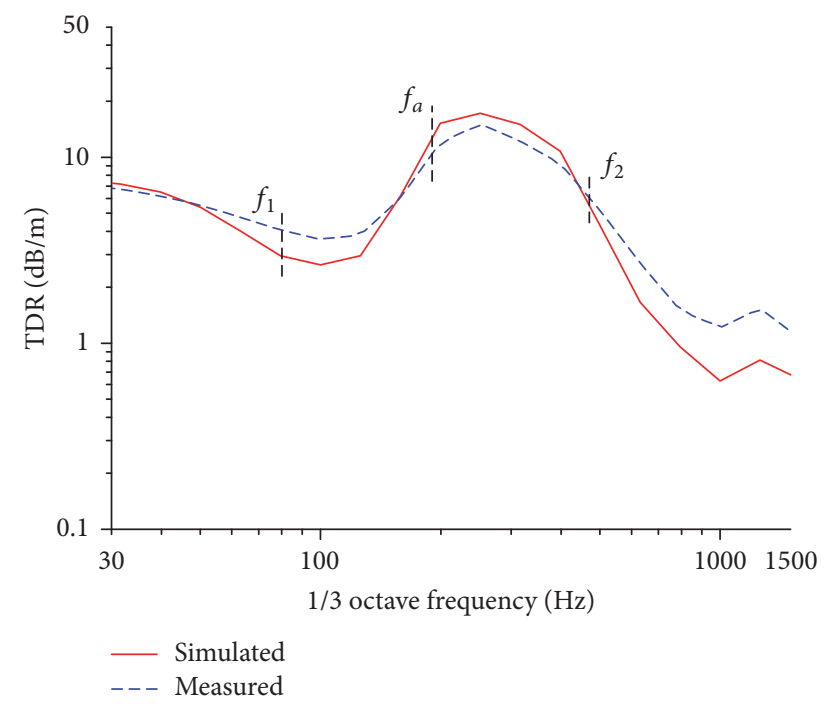

FIGURE 9: TDR of vertical rail vibration.

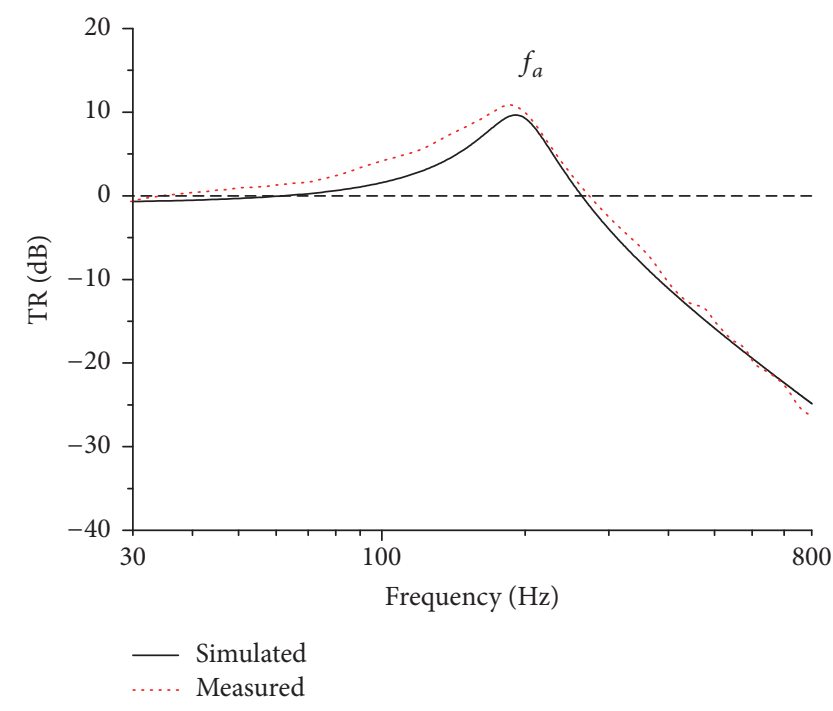

FIGURE 10: TR of vertical rail vibration. vibrate as a whole. The accelerance amplitude curves of the on-support rail and the sleeper both reach their peaks at $80 \mathrm{~Hz}$ where the phases are the same. Thus, the in-phase resonance of the rail and sleeper occurs at this frequency (denoted by $f_{1}$ ). At the antiresonance frequency of the onsupport rail (about $190 \mathrm{~Hz}$, denoted by $f_{a}$ ), the amplitude curve of the on-support rail reaches its trough. The sleeper resonates and acts as a dynamic vibration absorber of the rail. Amplitude curves of the on-support rail and the sleeper both reach their peaks at about $470 \mathrm{~Hz}$ where the phase difference is about $\pi$. Thus, the out-of-phase resonance of the rail and sleeper occurs at this frequency (denoted by $f_{2}$ ). It can also be seen in the amplitude curves of the sleeper. A trough appears in the amplitude curve of the on-support rail at $f_{p}=1337 \mathrm{~Hz}$ where the pinned-pinned antiresonance of the on-support rail occurs. The modal shape corresponds to a standing wave with nodes at the sleepers. The direct accelerances of on-support and mid-span rails are similar, except the only difference at $f_{p}$ where the accelerance amplitude curve of the mid-span rail reaches its peak.

3.3. Track Decay Rate. TDR of vertical rail vibrations is shown in Figure 9. The results are expressed in the form of one-third octave frequency spectrum.

As the solutions of the periodic track-substructure model contain two pairs of Bloch wave vectors, two TDRs can be obtained in the simulation. The first wave, known as the nearfiled wave, maintains a high decay rate in the whole frequency range. The second wave, known as the propagating wave, has a lower decay rate. Because the near-filed wave is attenuated greatly, the longwise transmission characteristics are reflected by the propagating wave. Figure 9 shows that the measured and simulated TDRs have the same changing trends though small value differences exist.

In the low frequency range, simulated TDR decreases with the increase of the frequency, until it starts increasing at $100 \mathrm{~Hz}$. The antiresonance frequency $f_{a}$ and the resonance frequency $f_{2}$ form the boundary frequencies of the highattenuation zone. Within this frequency range, the sleeper vibrates with high amplitude and absorbs much vibration energy from the rail. Above $f_{2}$, the TDR decreases again until a small peak corresponding to the bandgap of the periodic structure [26] occurs at $1260 \mathrm{~Hz}$. TDRs at high frequencies are relatively lower than those at low frequencies.

3.4. Transmission Rate. The transmission rate of vertical rail vibration is shown in Figure 10. The results are expressed in the logarithmic form $(20 \times \lg \mathrm{TR})$.

In the low frequency range, the TR increases with the increase of the frequency. At the antiresonance frequency $f_{a}$ of the rail, the TR curve reaches its peak and the downward vibration transmissibility is greatest. The sleeper resonates while the rail vibrates with low amplitude. In the frequency range of $150-250 \mathrm{~Hz}$, both TDR and TR are extremely high and the vertical rail vibrations are mostly transmitted downwards to the sleeper. Above $f_{a}$, the TR decreases with the increase of the frequency. At $800 \mathrm{~Hz}$, the TR is only $-25 \mathrm{~dB}$. In the high frequency range, both TDR and TR are low and therefore the vertical rail vibrations are mainly transmitted along the rail.

As simulations and measurements of the TDR and TR coincide well with each other, the presented models and methods in this paper are sufficient for studying the transmission characteristics of vertical rail vibrations.

\section{Parameter Study}

In this section, influences of different parameters on TDR and TR are investigated to further reveal the transmission characteristics of vertical rail vibrations.

4.1. Vertical Rail Pad Stiffness. Vertical rail pad stiffness determines the coupling degree between the rail and sleeper, directly affecting TDR and TR. The simulation results are 


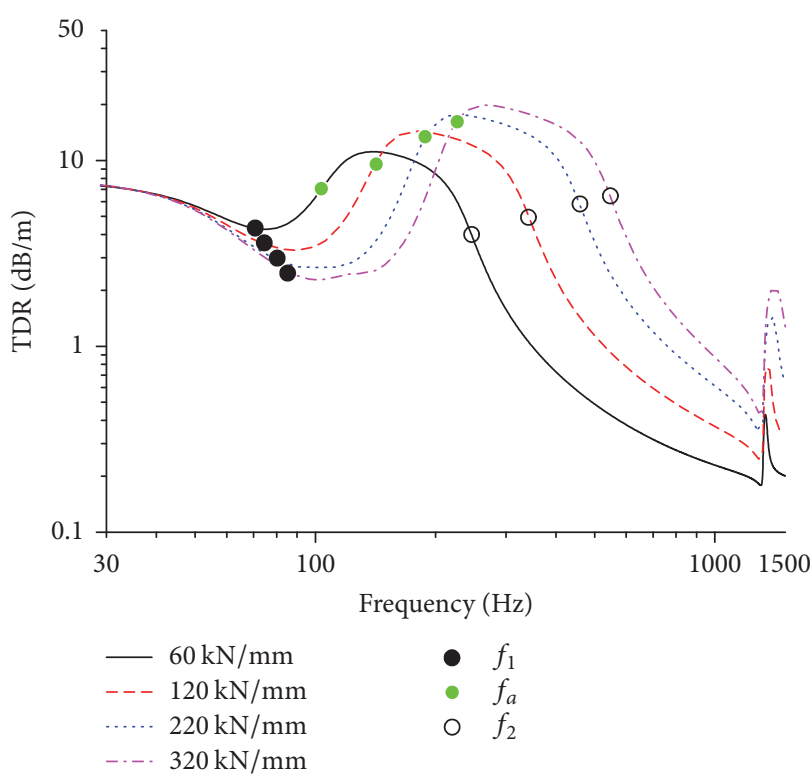

(a)

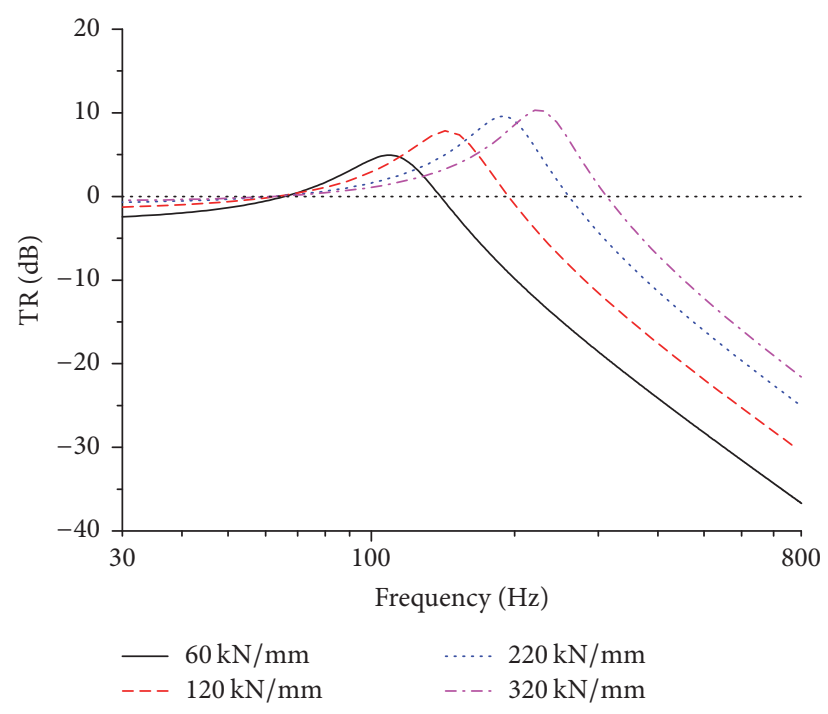

(b)

FIGURE 11: Influences of vertical rail pad stiffness on (a) TDR and (b) TR.

shown for vertical rail pad stiffness values of $60,120,220$, and 320 kN/mm in Figure 11.

With the increase of vertical rail pad stiffness, the coupling between the rail and sleeper is strengthened, and both the antiresonance frequency $f_{a}$ and the out-of-phase resonance frequency $f_{2}$ are increased, which moves the highattenuation zone into a higher frequency range. Additionally, the decay rate value of the high-attenuation zone gets higher. The rail pad stiffness has a little influence on the TDR below the in-phase resonance frequency $f_{1}$, because the rail and sleeper vibrate as a whole at low frequencies. However, the TDR increases with a stiffer rail pad above the antiresonance frequency $f_{a}$.

In the low frequency range, the TR is slightly influenced by the vertical rail pad stiffness. With the increase of the vertical rail pad stiffness, the frequency and value of the TR curve peak both get higher, and the TR value significantly increases at high frequencies.

It can be seen that the increase of vertical rail pad stiffness has a little effect on the transmission characteristics of vertical rail vibration in the low frequency range, but it can make more vibrations transmitted downwards to the sleeper above the antiresonance frequency of the rail.

4.2. Vertical Ballast Stiffness. Vertical ballast stiffness reflects the coupling degree between the sleeper and subgrade and also affects the transmission characteristics of vertical rail vibration. The simulation results are shown for vertical rail pad stiffness values of 20, 40, 60, and $80 \mathrm{kN} / \mathrm{mm}$ in Figure 12.

Figure 12 shows that ballast stiffness only influences the transmission characteristics below the antiresonance frequency of the rail. With the increase of vertical ballast stiffness, the TDR is significantly increased while the TR is decreased. Consequently, more vertical rail vibrations are transmitted to the subgrade and less ones are left on the sleeper or transmitted along the rail.

4.3. Rail Pad Damping Loss Factor. The existence of damping will dissipate the mechanical energy of the vibration system, which directly influences the transmission of vibration. The simulation results are shown for rail pad damping loss factor values of $0.1,0.25,0.5$, and 1 in Figure 13.

With the increase of the rail pad damping loss factor, the resonance of the sleeper will be mitigated, and therefore it will weaken the vibration absorption of the sleeper. As a result, the TDR in the high-attenuation zone is decreased. However, the TDR above the out-of-phase resonance frequency $f_{2}$ will be increased due to more energy dissipation of rails caused by rail pad damping.

The increase of the rail pad damping loss factor will decrease the TR near the antiresonant frequency $f_{a}$, which is also due to the mitigation of the sleeper vibration. The influences on TR in other frequency ranges are not significant.

4.4. Ballast Damping Loss Factor. The simulation results are shown for ballast damping loss factor values of $0.5,1$, and 2 in Figure 14.

The ballast damping loss factor mainly affects the TDR below the antiresonant frequency $f_{a}$. At low frequencies, the rail and sleeper vibrate as a whole. Therefore, the increase of the loss factor leads to a higher TDR due to the energy dissipation caused by ballast damping.

The ballast damping loss factor mainly affects TR near the antiresonant frequency $f_{a}$. With the increase of the loss factor, the TR gets lower and less vertical rail vibration is transmitted downwards to the sleeper. 


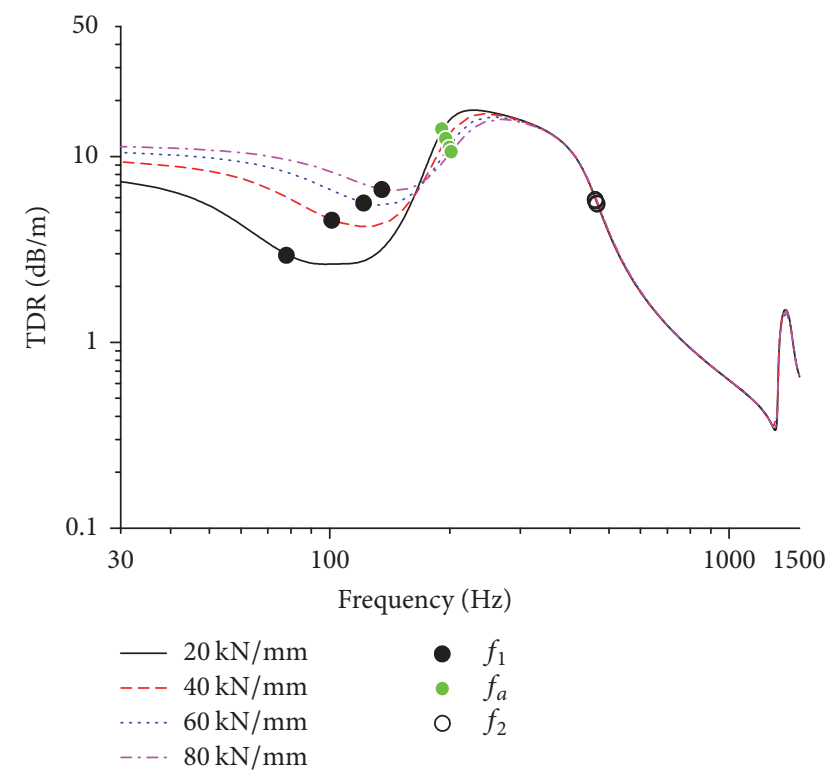

(a)

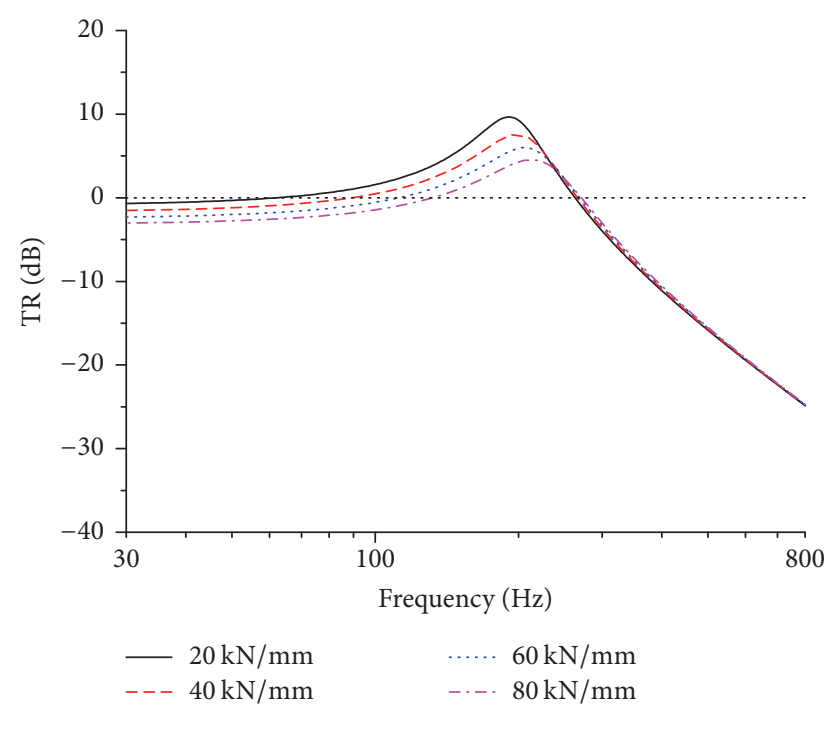

(b)

FIGURE 12: Influence of vertical ballast stiffness on (a) TDR and (b) TR.

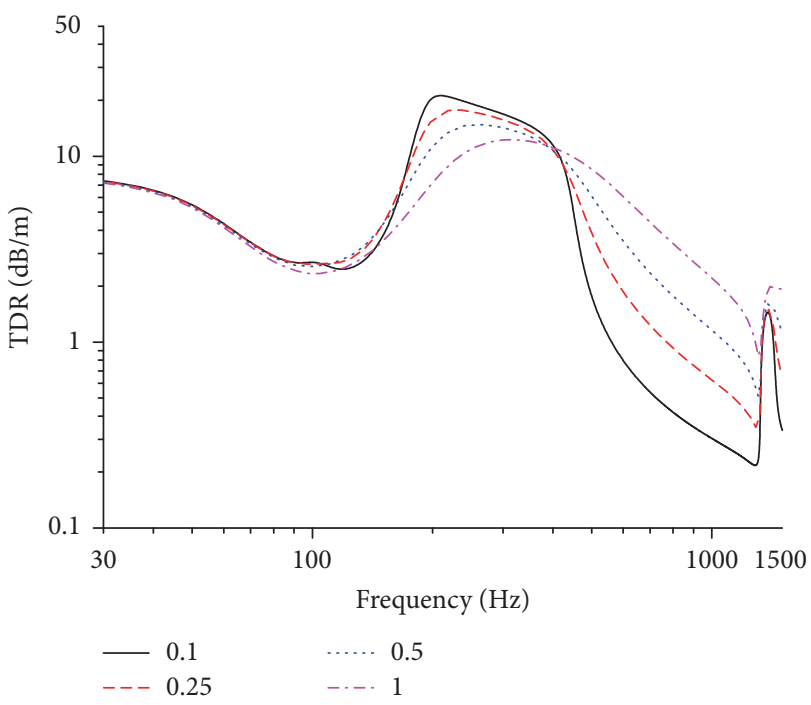

(a)

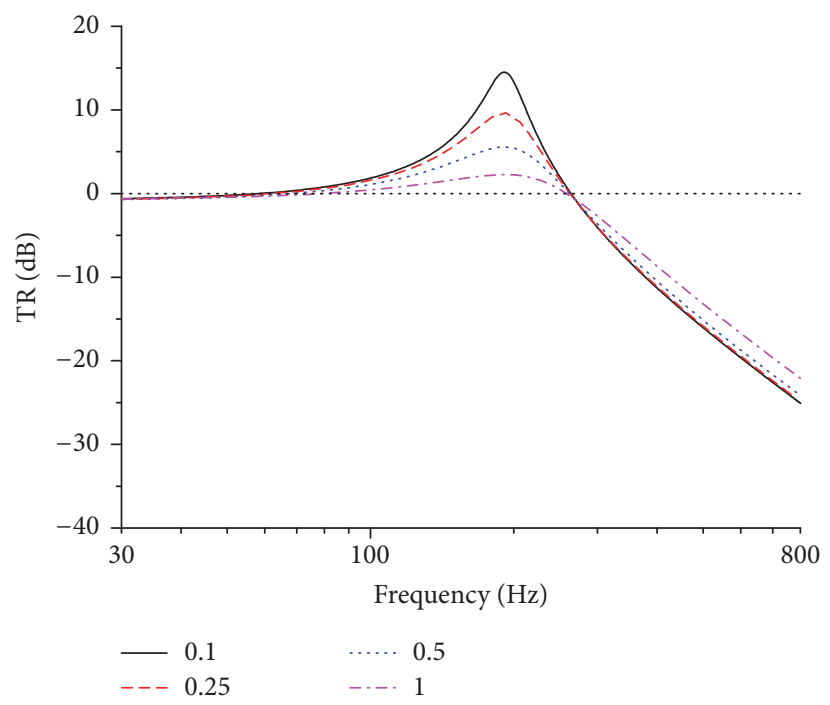

(b)

FIGURE 13: Influence of rail pad damping loss factor on (a) TDR and (b) TR.

4.5. Sleeper Mass. The simulation results are shown for sleeper mass values of 125, 150, and $170 \mathrm{~kg}$ in Figure 15.

The main influence of sleeper mass on the TDR and TR consists in changing the characteristic frequencies, leading to approximate transverse translations of TDR and TR curves. With the increase of sleeper mass, the characteristic frequencies $f_{1}, f_{a}$, and $f_{2}$ are decreased in different degrees, moving the curves towards the low frequency.

\section{Conclusion}

This paper investigates the transmission characteristics of vertical rail vibrations in the ballast track. The main conclusions can be drawn as follows.

(1) Simulations are well consistent with measurements, and the presented models and methods are sufficient for studying the TDR and TR of the vertical rail vibrations. 


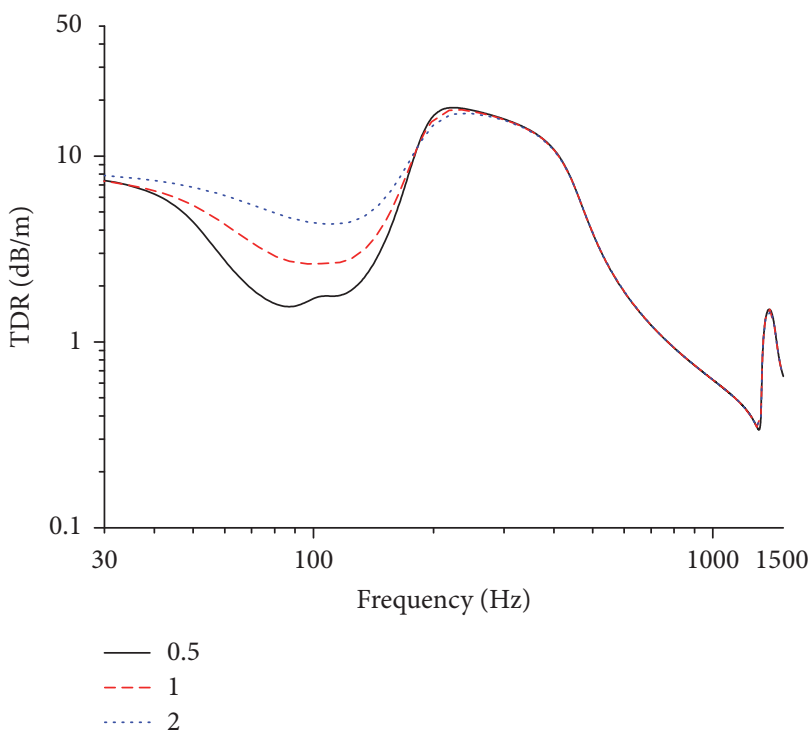

(a)

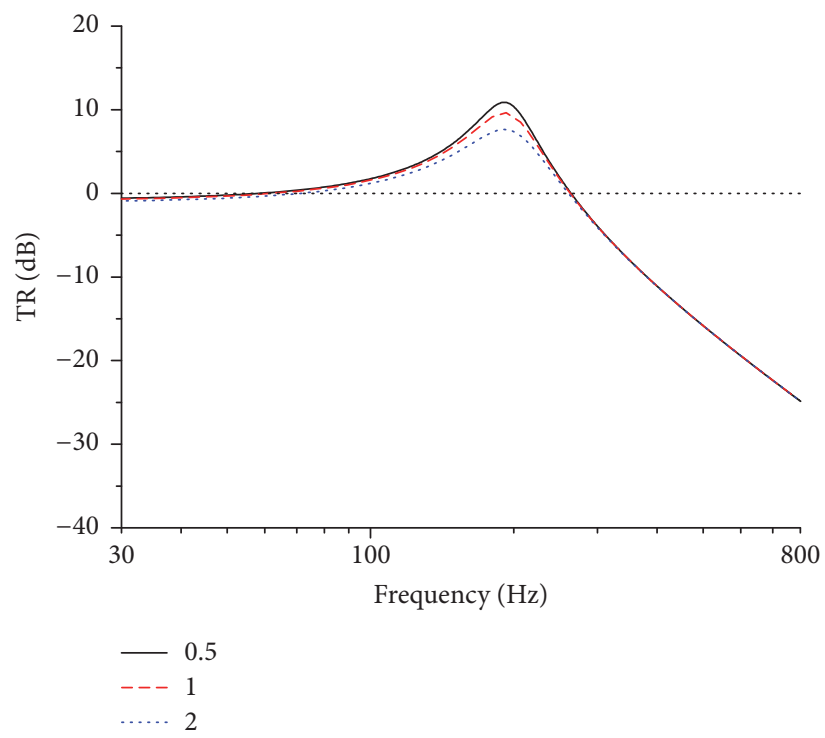

(b)

FIGURE 14: Influence of ballast damping loss factor on (a) TDR and (b) TR.

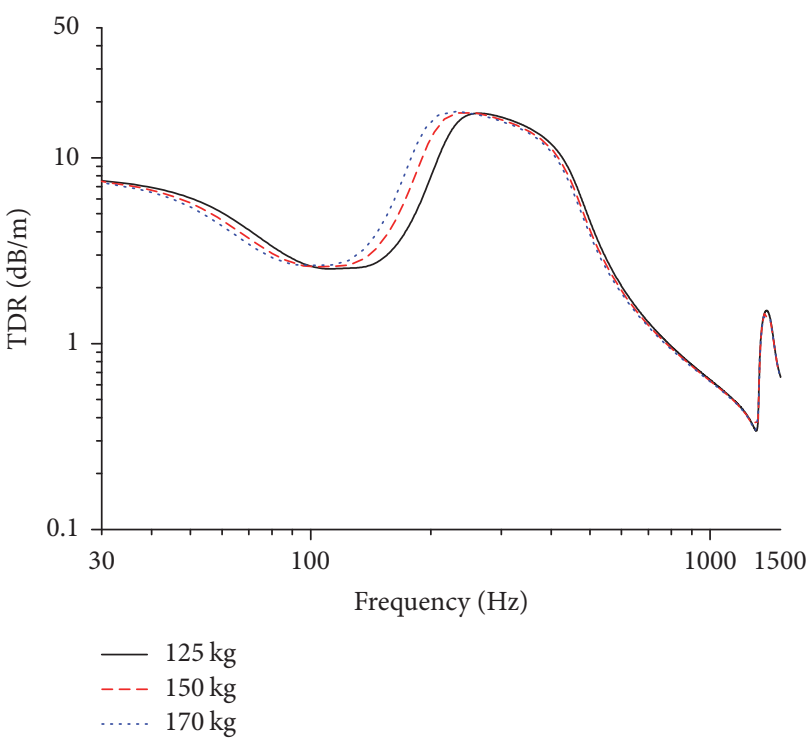

(a)

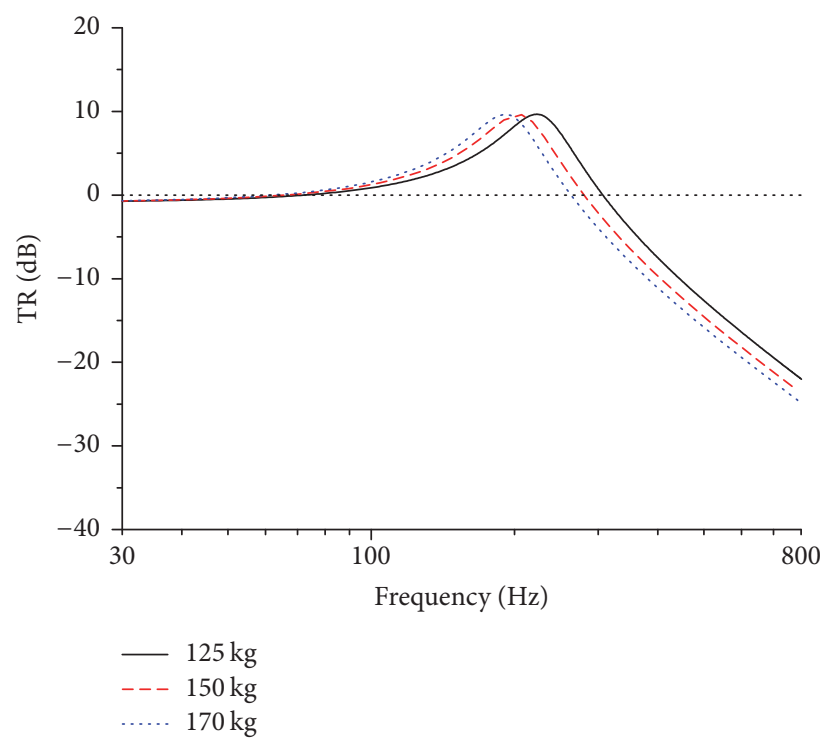

(b)

FIGURE 15: Influence of sleeper mass on (a) TDR and (b) TR.

(2) The antiresonance frequency of the rail and the out-of-phase resonance frequency of the rail and sleeper form the boundary frequencies of the high-attenuation zone for longwise vibration transmission, where the vibration absorption of the sleeper is significant. The TDR above the out-of-phase resonance frequency is lower than that below the antiresonance frequency.

(3) The TR curve reaches its peak at the antiresonance frequency of the rail, where the downward transmissibility of vertical rail vibrations is greatest. Above this frequency, the TR decreases with the increase of the frequency. The
TR in the high frequency range is lower than that in the low frequency range. Vertical rail vibrations are primarily transmitted downwards at low frequencies, while they are mainly transmitted along the rail at high frequencies.

(4) Stiffer rail pads can make more vibrations transmitted downwards to the sleeper above the antiresonance frequency of the rail, while stiffening of the ballast makes more vertical rail vibrations transmitted to the subgrade and less ones left on the sleeper or transmitted along the rail below the antiresonance frequency. The rail pad damping will weaken the vibration absorption of the sleeper, making more vertical 
rail vibrations transmitted along the rail within the highattenuation zone. The main influence of sleeper mass consists in changing characteristic frequencies.

The work in this paper can be helpful to find the reasons for problems of large noises and vibrations for the ballast track.

\section{Conflicts of Interest}

The authors declare that they have no conflicts of interest.

\section{Acknowledgments}

The work in this paper was supported by the National Natural Science Foundation of China (nos. 51425804 and 51508479) and the Research Fund for the key research and development projects in the Sichuan Province (2017GZ0373).

\section{References}

[1] C. J. C. Jones, D. J. Thompson, and R. J. Diehl, "The use of decay rates to analyse the performance of railway track in rolling noise generation," Journal of Sound and Vibration, vol. 293, no. 3-5, pp. 485-495, 2006.

[2] W. Li, R. A. Dwight, and T. Zhang, "On the study of vibration of a supported railway rail using the semi-analytical finite element method," Journal of Sound and Vibration, vol. 345, pp. 121-145, 2015.

[3] B. Betgen, G. Squicciarini, and DJ. Thompson, "On the prediction of rail cross mobility and track decay rates using finite element models," in Proceedings of the In Proceedings of the 10th European Congress and Exposition on Noise Control Engineering, p. 2019, 2015.

[4] K. Knothe and Y. Wu, "Receptance behaviour of railway track and subgrade," Archive of Applied Mechanics, vol. 68, no. 7-8, pp. 457-470, 1998.

[5] W. M. Zhai, K. Y. Wang, and J. H. Lin, "Modelling and experiment of railway ballast vibrations," Journal of Sound and Vibration, vol. 270, no. 4-5, pp. 673-683, 2004.

[6] S. Kaewunruen and A. M. Remennikov, "Field trials for dynamic characteristics of railway track and its components using impact excitation technique," NDT \& E International, vol. 40, no. 7, pp. 510-519, 2007.

[7] H. Chebli, D. Clouteau, and L. Schmitt, "Dynamic response of high-speed ballasted railway tracks: 3D periodic model and in situ measurements," Soil Dynamics and Earthquake Engineering, vol. 28, no. 2, pp. 118-131, 2008.

[8] M. Esmaeili, J. Sadeghi, and M. Fesharaki, "Vehicle dynamic interaction with railway track embankment," Proceedings of the Institution of Civil Engineers: Transport, vol. 167, no. 1, pp. 15-26, 2015.

[9] F. Shirmohammadi, S. Bahrami, M. M. Saadatpour, and A. Esmaeily, "Modeling wave propagation in moderately thick rectangular plates using the spectral element method," Applied Mathematical Modelling, vol. 39, no. 12, pp. 3481-3495, 2015.

[10] Z.-J. Wu, F.-M. Li, and C. Zhang, "Vibration band-gap properties of three-dimensional Kagome lattices using the spectral element method," Journal of Sound and Vibration, vol. 341, pp. 162-173, 2015.
[11] U. Lee and I. Jang, "Spectral element model for axially loaded bending-shear-torsion coupled composite Timoshenko beams," Composite Structures, vol. 92, no. 12, pp. 2860-2870, 2010.

[12] H. Igawa, K. Komatsu, I. Yamaguchi, and T. Kasai, "Wave propagation analysis of frame structures using the spectral element method," Journal of Sound and Vibration, vol. 277, no. 4-5, pp. 1071-1081, 2004.

[13] U. Lee, Spectral Element Method in Structural Dynamics, John Wiley and Sons Inc., New York, NY, USA, 2009.

[14] Man APD, A Survey of Dynamic Railway Track Properties and Their Quality, Delf University Press, 2002.

[15] K. F. Graff, Wave Motion in Elastic Solids, Clarendon Press, Oxford, UK, 1975.

[16] J. F. Doyle, Wave Propagation in Structures, Springer-Verlag Inc., New York, NY, USA, 2nd edition, 1989.

[17] O. C. Zienkiewicz et al., The Finite Element Method, McGrawhill, London, UK, 1977.

[18] G. Carta and M. Brun, "Bloch-Floquet waves in flexural systems with continuous and discrete elements," Mechanics of Materials, vol. 87, pp. 11-26, 2015.

[19] R. Esquivel-Sirvent, "Band Structure for the Propagation of Elastic Waves in Superlattices," The Journal of the Acoustical Society of America, vol. 95, no. 1, pp. 86-90, 1994.

[20] G. Carta, M. Brun, and A. B. Movchan, "Dynamic response and localization in strongly damaged waveguides," Proceedings of the Royal Society A Mathematical, Physical and Engineering Sciences, vol. 470, no. 2167, Article ID 20140136, 2014.

[21] J. Ryue, D. J. Thompson, P. R. White, and D. R. Thompson, "Decay rates of propagating waves in railway tracks at high frequencies," Journal of Sound and Vibration, vol. 320, no. 4-5, pp. 955-976, 2009.

[22] D. J. Thompson, "Wheel-rail noise generation, part III: rail vibration," Journal of Sound and Vibration, vol. 161, no. 3, pp. 421-446, 1993.

[23] P. M. Fernández, I. Villalba Sanchís, F. Botello Rojas, and R. Insa Franco, "Monitoring and analysis of vibration transmission for various track typologies. A case study," Transportation Research Part D: Transport and Environment, vol. 24, pp. 98-109, 2013.

[24] BSI, BS EN 15461: 2008+A1, 2010, Railway Applications-Noise Emission-Characterization of the Dynamic Properties of Track Selections for Pass by Noise Measurements, BSI, London, UK, 2010.

[25] D. J. Thompson and V. Nicolas, "Track dynamic behaviour at high frequencies. Part 1: theoretical models and laboratory measurements," Vehicle System Dynamics, vol. 24, no. 1, pp. 8699, 1995.

[26] D. J. Mead, "Wave propagation and natural modes in periodic systems: I. Mono-coupled systems," Journal of Sound and Vibration, vol. 40, no. 1, pp. 1-18, 1975. 


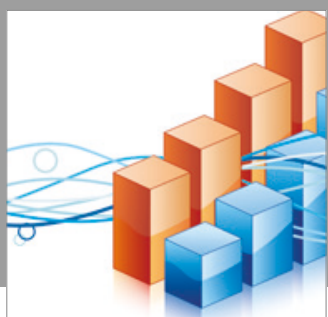

Advances in

Operations Research

vatersals



\section{The Scientific} World Journal
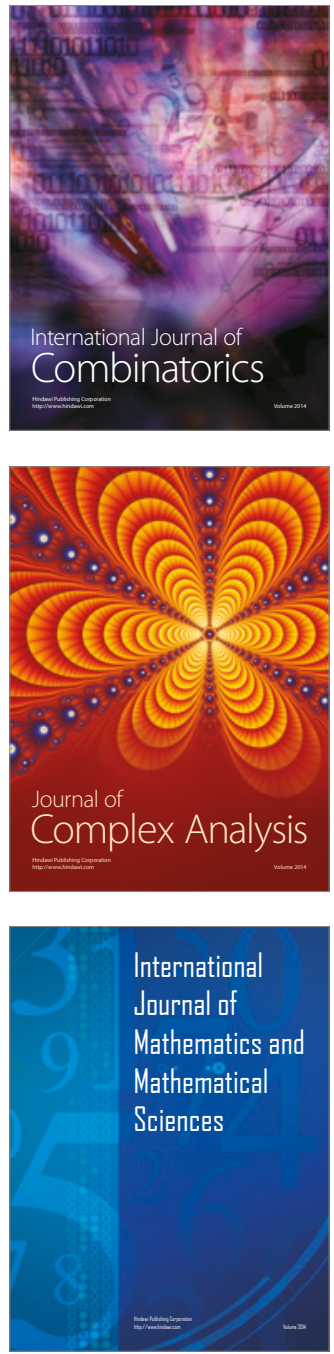
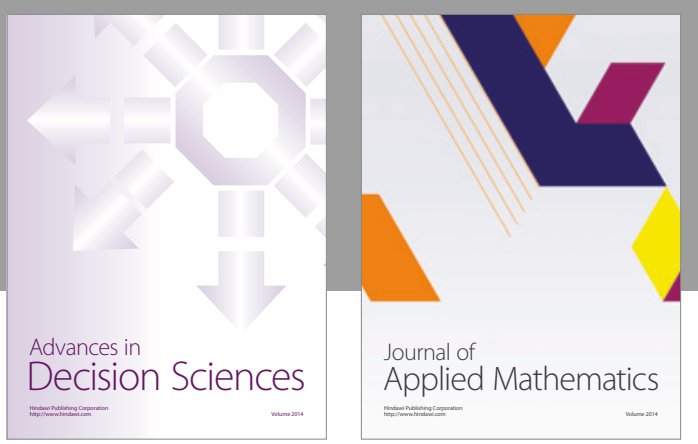

Algebra

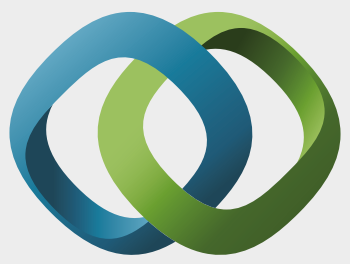

\section{Hindawi}

Submit your manuscripts at

https://www.hindawi.com
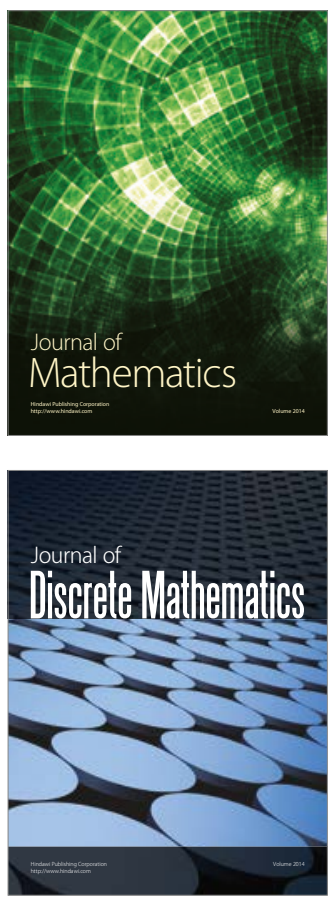

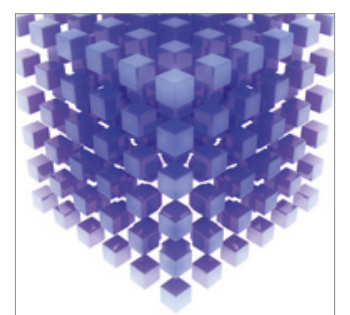

Mathematical Problems in Engineering
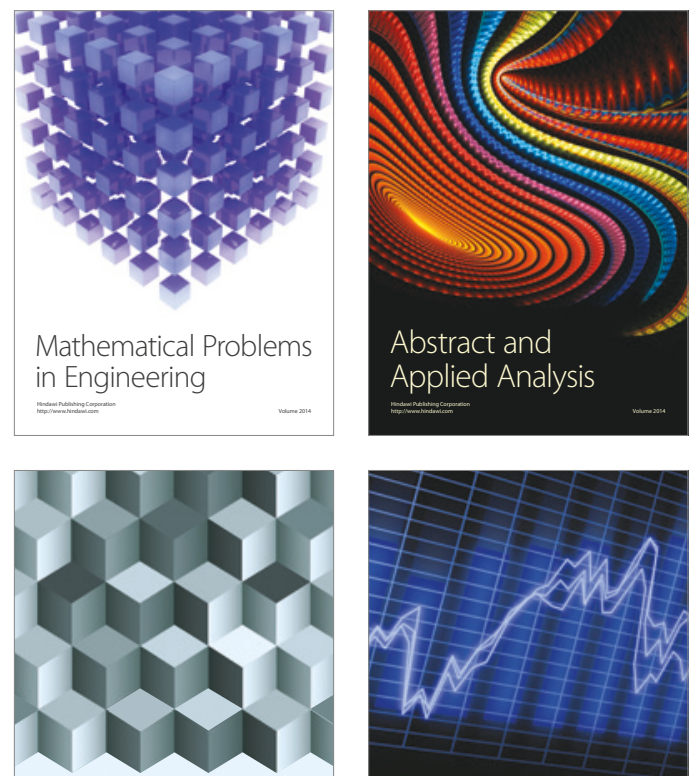

Journal of

Function Spaces

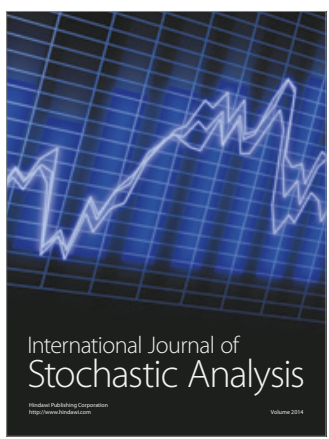

Probability and Statistics
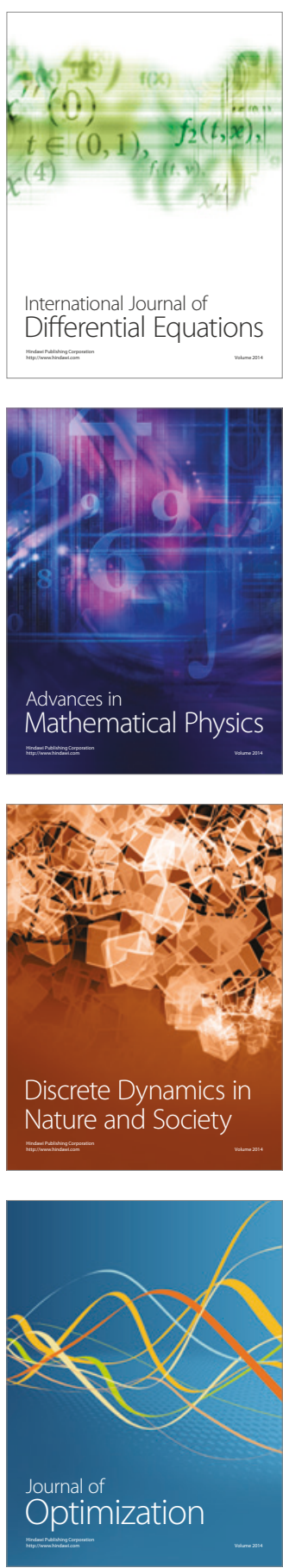